\title{
Monaldi Archives for Chest Disease - Cardiology Area: An essential instrument for the Italian Association of Cardiac Prevention and Rehabilitation (GICR-IACPR)
}

\author{
Carlo Vigorito ${ }^{1}$, Pompilio Faggiano ${ }^{2}$ \\ ${ }^{1}$ Federico II University of Naples; ${ }^{2}$ Spedali Civili, Brescia, Italy
}

\begin{abstract}
At the beginning of the triennium 2019-2022, as Editors of the Monaldi Archives for Chest Disease - Cardiology Area, we would like to share with all cardiologists and allied health professionals working in cardiovascular prevention and rehabilitation the status of our Journal, which is the official Journal of the Italian Association of Cardiac Prevention and Rehabilitation (GICR-IACPR), and has contributed in these past years, thanks to effort and dedication of all Editors who have preceded us, to the advancement of our profession, and to an enrichment and dissemination of its scientific contents. The Monaldi Archives for Chest Disease will remain an important instrument of the Italian Association of Cardiac Prevention and Rehabilitation for discussing internal organization, diffusing the activity and research of Cardiac Rehabilitation in Italy and other Countries, and important guidelines and position papers.

As you may have appreciated, the Journal is becoming every year more attractive for those willing to publish their work, due to the open access format, the free of charge publication, the rigorous peer review system, the link to the most important international databases and a professional editorial governance. This has also led to the improvement of the quality of the contributions and to an enlarging appreciation and recognition from the scientific world. Starting from these points we will make every effort to consolidate these results and to reach in the near future a greater impact in the scientific community.

We therefore would like to recognize and give credit to all the authors that have submitted their manuscripts, to all reviewers that
\end{abstract}

have provided a careful selection and guaranteed scientific level of published papers, to the Editorial Board members and Managing Editor that allowed us to maintain the quality of publications coupled with a fast paper editorial track.

However, there is always room for improvement. Therefore, we will enlarge the Editorial board panel to other qualified member of our national and international scientific community, in an effort to increase even more the recognition of the Journal as an important contributor to the advancement of Cardiovascular Prevention/Rehabilitation. This will also help us to enrich the ground of potential contributors and to render more efficient and timely the evaluation process of papers. We will also stimulate the deepening of important papers by asking dedicated invited editorials and reviews on topics of particular interest and actuality. We thank all those colleagues who have accepted to be part of our Editorial board, and trust that their participation will be active and constructive. A list of all reviewers who dedicated time to review submitted papers in 2018 has been already published in the issue 1, Vol. 89 (2019) of the Journal.

Particular thanks to the ICS Maugeri, who have guaranteed us an absolute independence in the editorial lines of the Cardiology Area of the Journal, as an expression of the consolidated relationship with our Italian Association of Cardiac Prevention and Rehabilitation, and confirmed their commitment to the diffusion of knowledge of cardiovascular rehabilitative medicine.

The Editors - Cardiology Area Carlo Vigorito Pompilio Faggiano

Correspondence: Carlo Vigorito, Federico II University of Naples, Italy.

E-mail: vigorito@unina.it

Key words: Cardiovascular rehabilitative medicine; prevention; GICR-IACPR.

Received for publication: 12 June 2019

Accepted for publication: 13 June 2019.

(C) Copyright C. Vigorito and P. Faggiano, 2019

Licensee PAGEPress, Italy

Monaldi Archives for Chest Disease 2019; 89:1111

doi: 10.4081/monaldi.2019.1111

This article is distributed under the terms of the Creative Commons Attribution Noncommercial License (by-nc 4.0) which permits any noncommercial use, distribution, and reproduction in any medium, provided the original author(s) and source are credited. 